\title{
A transformational study abroad process model for nursing educators consideration
}

\author{
Grace E. Moorefield* \\ School of Nursing, Azusa Pacific University, Azusa, California, United States
}

Received: September 26, 2017

Accepted: October 22, 2017

Online Published: October 27, 2017

DOI: $10.5430 /$ jnep.v8n3p23

URL: https://doi.org/10.5430/jnep.v8n3p23

\begin{abstract}
Objective: Preparing nursing students within the college or university setting to make a positive difference in today's global society increasingly includes opportunities to study abroad. Maximizing the transformational benefits of these experiences while minimizing the potential ill effects must be a focus of those who develop and implement these programs. This research was conducted to better understand the entire study abroad experience from the student point of view in order to develop a holistic model for nurse educators to utilize in the development of curricular and support programming.

Methods: A descriptive, qualitative survey with 72 baccalaureate nursing and other art and science degree alumni from a mid-sized, private, Christian university in the United States who studied for a semester in a third world country was conducted. These participants provided essay answers to four questions regarding the impact, challenges, and opportunities appreciated throughout their study abroad experience, as well as recommendations for future study abroad programming. The responses were analyzed and the results compared with the theoretical framework upon which the study was based.

Results and conclusion: Five major components of a transformative study abroad experience were exemplified. The first related to the characteristics of the sojourner, and the remaining four to a comprehensive patterned experiential process by which students moved through their study abroad experience towards transformation and action. The findings provide both a conceptual model and practical insights for nurse educators to consider as they prepare future nurses to engage their world for good through study abroad experiences.
\end{abstract}

Key Words: Study abroad, Transformation, Disillusionment, Nursing, Nursing curriculum, Theoretical model

\section{INTRODUCTION}

Metamorphosis of a college or university student into a working professional ready and able to contribute to today's society is an anticipated outcome of higher education. For nursing students in particular, learning to provide culturally competent patient-centered care is a requirement. ${ }^{[1]}$ Understanding the change process and maximizing the potential of each student as they engage in the increasing number of educational opportunities for study abroad is crucial to meeting this obligation. When study abroad programming is done with a limited understanding of the experience in its entirety (before, during and after), there is the potential for negating the benefits of studying abroad and decreasing future nurses' global understanding and readiness to engage the world for good through their nursing care. ${ }^{[2-5]}$ Academic study abroad opportunities for nursing students rooted in sound theory-based research findings are essential to the preparation of nursing professionals for the twenty-first century global workplace.

\footnotetext{
*Correspondence: Grace E. Moorefield; Email: gmoorefield@ apu.edu; Address: School of Nursing, Azusa Pacific University, Azusa, California, United States. 
There is over 30 years of research and literally hundreds of scholarly articles that portray various aspects of university and college study abroad experience applicable to nursing study abroad. For example, Comp referenced approximately 651 documents published between 1988-2000, and an additional 223 documents between 2000-2003. ${ }^{[6,7]}$ Biscarra added to Comps collected annotated bibliographies raising the number to over 853 references prior to 2004 and another 573 references between 2004 to 2011. ${ }^{[8,9]}$ Parcells, O'Brien and Woodrugg provided a listing of 121 articles, Weber another bibliography of 140 resources, and Levine provided 45 sources focused on various aspects of shortterm and semester study abroad programs for baccalaureate nursing students specifically. ${ }^{[10-12]}$ Among the plethora of information that spans the years of available research are rich descriptions of many aspects of the study abroad experience, profiles of those who studied abroad, theories explaining components of the study abroad experience, formal tools for evaluating elements of students' characteristics and experiences abroad, appeals to engage in the development of more comprehensive theoretically based programming, general recommendations for programming, arguments for the value of study abroad, and claims of positive outcomes achieved. However, there is limited evidence of comprehensive curricular and support programming outcomes that substantiate assertions of program success and student transformation through study abroad.

In fact, the downside of the study abroad experience is also present in the literature. Obstacles to growth and transformation before, during and after return that thwart student success are at times glaringly evident, and at other times become apparent when reading between the lines. For example, there are numerous articles describing the negative impact of culture shock, ${ }^{[13-16]}$ reentry or reverse culture shock, ${ }^{[17-25]}$ and evidence of maladjustment even years after students return. ${ }^{[26-31]}$ These negative outcomes, have at times shackled students personally and professionally, depriving them of the full benefit of studying abroad that they sought when they applied to go abroad. ${ }^{[32-36]}$

If even a relatively small number of study abroad nurse alumni find themselves coping with buried and/or unresolved grief as a result of the devastating suffering they have witnessed abroad, or if they are unable to make peace with their feelings of differentness, confusion, threat, loneliness, and disappointment in relationship to self and others that surfaced in-tandem with the study abroad experience, ${ }^{[37-46]}$ might the full benefit of the study abroad experience be lost to these individuals, as well as to the global community they are preparing to serve? And, if theoretically sound programs are not in place to sufficiently address the needs of all nursing students who study abroad, will not the casualty numbers grow as more opportunities to study abroad are made available?

Psychological adjustment problems will continue to lead to more anxiety and depression diagnoses, insufficient support and relationship problems will impede professional growth, learning opportunities will be lost in the process, and academic difficulties will continue to interfere with career success of the graduating nurse, not to mention the potentially negative long-term effects also described in many of these studies. ${ }^{[47-58]}$ If indeed the "future of nursing is international", nursing educators have a responsibility to prepare nurses who are able to take action focused on meeting the healthcare needs of "our neighbors" globally. ${ }^{[59]}$ Thus, the purpose of this research was to better understand the study abroad experience in its entirety from the students' points of view; not just the successes, but the pitfalls and potential remedies, in an effort to capture the process by which transformational learning takes place in students and to identify specific elements of curricular and support programing that need to be included in study abroad programming, particularly for nursing students, in order to maximize their academic transformative success through studying abroad.

\section{THEORETICAL FRAMEWORK}

The theoretical perspectives of Thompson and Christofi, Milstein, and Shougee, provided a basis for understanding the study abroad student experiences. ${ }^{[60-63]}$ Thompson and Christofi combined Piaget's theory of equilibrium and Adler's re-acculturation coping styles to explain how a student struggles to adjust to their new environment when going abroad and upon return. ${ }^{[64-66]}$ They described how a student's struggle results in a cognitive unbalancing (disequilibrium) in the student where their natural tendency to organize and adjust is activated and they learn to accommodate (rework) their understanding of themselves, others, and their environment in such a way that they are able to regain their balance (equilibrium) and adapt. ${ }^{[67]}$ During this process, a student who possesses the characteristics of optimism and "proactive coping" is more likely to experience positive change and transform as opposed to a student who focuses on feelings of rejection and rebelliousness. ${ }^{[68]}$

Milstein, borrowing from Kim and Ruben's Intercultural Transformation Theory and Bandura's Social Learning Theory, proposed that it is the stress itself that becomes the student's motivator for adjusting their values, beliefs, and attitudes. During these times of stress, a student's perception that they have the cognitive, behavioral, and self-regulatory abilities to take the right action in the midst of challenging adversity becomes their most effective source for rebalanc- 
ing, adapting to their changing world and transforming. ${ }^{[69-71]}$ According to Shougee, a transformation of perspective, as theorized earlier by Mezirow, takes place over time; from the moment a student first considers going abroad, throughout their time abroad, after they return, and into their future. As the student's self-awareness, self-confidence and sense of autonomy and relatedness increases, their worldview expands, and they gain a clearer direction for their life. This transformation involves a letting go of what was, mourning the loss of past experiences, people, and their previous ways of understanding the world, and culminates in positive social action. ${ }^{[72,73]}$

Proposed transformational study abroad process model The proposed transformational study abroad process model that served as the framework for this study is a compilation of this author's understanding of the above-mentioned theoretical perspectives (see Figure 1). According to the proposed model, the traits, coping styles, and attitudes, as well as the student's motivational response to stress and perceived ability to master difficult situations, all contribute to the sojourner's ultimate ability to transform. The student's level of stress, and their ability to let go of what they knew prior to their sojourn, to rework their values and beliefs about the world, and to make sense of themselves in relationship to others and the world in general, all impact their ability to adapt, the degree of disillusionment they experience, and the degree of transformation that takes place within them. The transformation, when actualized, results not only in the expansion of the student's worldview, but positive action taken on behalf of others.

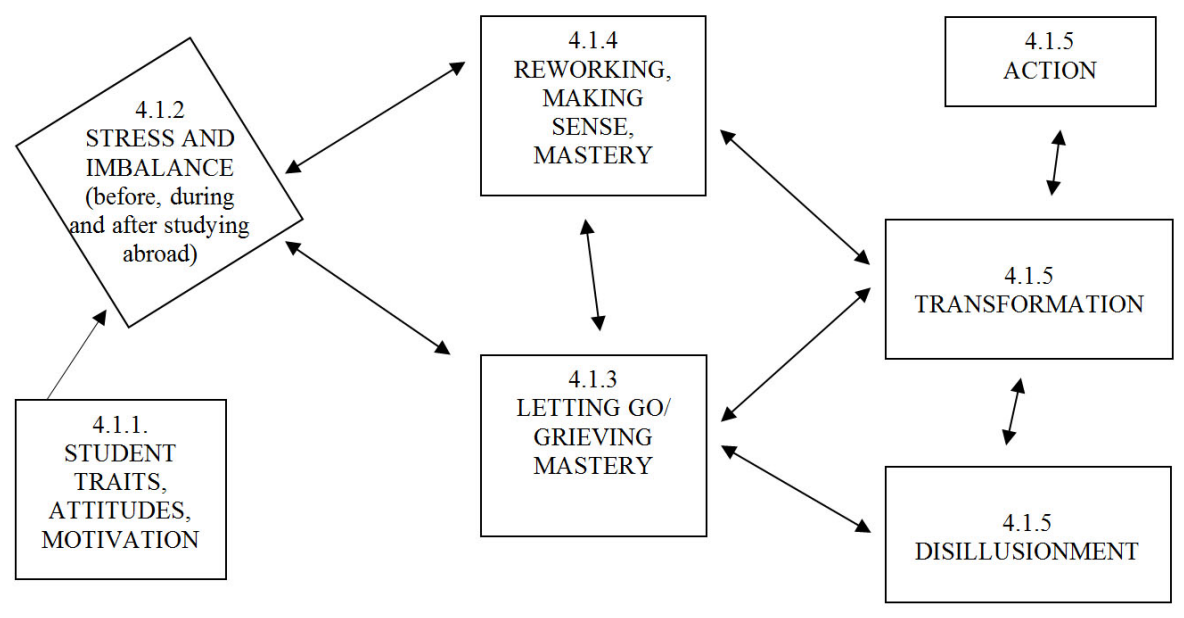

Figure 1. A transformational study abroad process model

Each student comes to the study abroad experience with their own unique personalities, skill-sets, life experiences, and beliefs about themselves in relationship to the world they have lived in. Once they engage in the study abroad experience, their personal traits, their attitudes about life, and what motivates and drives them, are all put to the test and varying degrees of stress develop. The stress causes a shake-up of values, beliefs, and attitudes once held by the student. This stress, coupled with the lack of understanding of these changes, leads to a cognitive, as well as an emotional imbalance (disequilibrium) inside of the student. When the student experiences this disorientation of thought and the emotional upheaval internally, they are prompted by their natural internal inclination to try to adapt. Motivated by the loss of what was familiar in the past, they must grieve what is no longer their once held reality.

As the student is able to think at a deeper level about who they are as an individual and as a person in relationship with others and the world, reevaluate their values and beliefs about life, let go of (grieve) the past, and embrace their new truth or reality, they are able to change, grow, and transform. Evidence that this transformation is taking place in a student nurse, for example, is recognized by an increased desire to or actual engagement in opportunities to advocate on behalf of others in need of healthcare, that prior to their sojourn may not have been on their intellectual or emotional radar. Unfortunately, a student who is wrought with a pessimistic viewpoint of their experience abroad, who has a sense that others somehow control their destiny, including the outcome of their study abroad experience, and/or who is unable to open themselves to change regarding how they see themselves, others and the world, may get stuck in their grief and remain disillusioned, possibly even for years. Unmitigated, physical, emotional, and/or intellectual pain and mal-adaptation instead of transformation may result. Under- 
standing this process of transformation, including the pitfalls along the way, is the first step towards developing holistic curricular and support programming that maximizes the benefits of studying abroad.

\section{MEthod}

In order to test the proposed model of the transformation process, the personal experiences of students who studied abroad were elicited as part of a larger mixed methods survey. The descriptive, qualitative analysis was based on a convenience sampling of 72 alumni from a mid-sized, private Christian university in the United States who had studied for a semester in a third world country while obtaining their baccalaureate degrees. The sample was comprised of 23 Bachelor of Science in Nursing (B.S.N.) majors and 49 Bachelor of Science or Art in other (B.A./B.S.) majors (see Table 1). Their coursework included the study of the cultural history of their country of sojourn, intercultural communications, and community engagement practicums. Approximately half $(n=35$, $49 \%$ ) of the participants had returned from their semester abroad less than 18 months prior to the time when the survey was conducted. The others $(n=37,51 \%)$ had returned from their semester abroad 18 months or more at the time of the survey.

Table 1. Participants self-reported majors $(\mathrm{N}=72)$

\begin{tabular}{|c|c|c|c|c|c|c|c|}
\hline Major & $\mathbf{N}$ & Major & $\mathbf{N}$ & Major & $\mathbf{N}$ & Major & $\mathbf{N}$ \\
\hline Nursing & 23 & Psychology & 5 & Art & 3 & English & 1 \\
\hline Liberal Arts & 7 & Business & 4 & Undeclared & 3 & Global Studies & 1 \\
\hline Communications & 6 & Christian Ministry & 4 & Theatre & 2 & History & 1 \\
\hline Social Science & 6 & Social Work & 4 & Applied Exercise Health & 1 & Music & 1 \\
\hline
\end{tabular}

Internal Review Board (IRB) approval was obtained prior to conducting this research from the university where the research was to be conducted. Once IRB approval was obtained, the survey, along with the consent to participate and a list of mental health resources, was sent from the study abroad office via the web based tool Survey Guizmo to a convenience sampling of 315 potential participants. Seventytwo anonymously responded, in writing, to the following four essay questions:

(1) Describe the opportunities you appreciated in your study abroad experience.

(2) Describe how your study abroad experience impacted you.

(3) Describe the challenges you faced in your study abroad experience.

(4) Please share your advice regarding how university leaders could improve the study abroad experience for students.

Each of the responses ranged from a single sentence to more than four paragraph long answers to each of the four questions. The content of the essays was analyzed and the themes tabulated, coded and grouped into categories. The categories were then clustered in sections (components), sequenced (before, during and subsequent to their sojourn), and then compared to the theoretical framework derived from the literature for this study.

\section{Findings}

The 72 participants provided 279 written responses to the four questions related to the opportunities they appreciated, the impact and challenges of studying abroad, and their advice to university leaders. They described opportunities for cultural engagement (26 entries) and relationship building with the nationals (24 entries), relationship building with peers and staff (17 entries), spiritual development through activities such as prayer, devotional reading and meditation (15 entries), service specifically focused on others who were suffering (7 entries), classroom and clinical learning (26 entries), and adventure/travel (25 entries). Weaved throughout their responses were descriptions of five components of the transformative process that were consistent with earlier literature and the theoretical framework utilized for this study. The components included: 1) traits, attitudes and motivation, 2) stress and imbalance, 3 ) letting go and grieving, 4) reworking, making sense and mastery, and 5) disillusionment and/or transformation (see Figure 1). The first component focused primarily on the characteristics of the sojourner. The other four focused more on the evolutionary process of the study abroad experience, prior to, during, and after. In addition to the transformational process data, participants provided recommendations for improvement that clustered into four main categories: program and administrative concerns, purpose for studying abroad, cultural immersion opportunities, and student support, as well as a smattering of comments of gratitude for the experience. 


\subsection{Components of the transformational process}

\subsubsection{Traits, attitudes, and motivation}

The participants frequently talked about how their personal traits (characteristics) impacted their experience, the attitudes they held, and their natural motivational tendencies and drive to adjust to changes in their world. Twenty-two (31\%) discussed, at some length, their personal traits and how they believed these characteristics impacted their success and the transformation they ultimately enjoyed. They wrote about such traits as independence, self-reliance, determination, and self-sufficiency, each of which is consistent with having an internal sense of responsibility for their own successes in life. Another five (7\%) of the participants wrote about how they blamed others for their negative experiences saying things like, "others ruined the trip for me", "they failed to ask," "they were clique-y," and they did not "like what I liked so I didn't get much out of it...". These were examples indicative of people whose beliefs about their ability to be successful was more external, dependent on others responses to them. One entry read, for example:

It was tough. Nothing to do with the culture or the people there, but because of my fellow [name of school] students that came. As a whole, they were exclusive and I felt very rejected. I didn't make very good friends, and even lost some old ones. Because of these relationship problems, I do not look on my study abroad experience warmly. Yes, I did have some great experience, but overall, the feelings of rejection are what stand out the most. These feelings continue to have a role in my life today.

There were candid responses by others who owned their own struggles with issues such as not being able to get close to others easily; being too self-involved, being fearful of failing, worrying about the future, having a hard time serving those who are different from them, and having to work hard to overcome these predispositions. Still others wrote about their own struggle within to stay positive amidst difficult situations with which they had to cope, and to make "my experience my own and not being swayed by others in their negative experiences or by trying to compare my experience". In addition, participants described a motivation to further develop virtues such as compassion and sympathy for the plight of others through studying abroad. Words such as "grateful", "blessed", "thankful", and "fortunate" were sprinkled throughout the 67 answers to the essay question, describe the opportunities you appreciated in your study abroad experience, exemplifying the attitudes and the motivation with which they entered into difficult situations and "struggled"

Published by Sciedu Press to adapt. A sampling of traits, attitudes, and motivations are exemplified in this entry:

I went into the experience hoping for something, I just didn't quite know what it was that I was hoping for.... I was determined to have a good and meaningful experience [country removed], but I was also determined not to come back bitter towards the country I grew up in, the U.S. I feel like I was able to balance the two well. I definitely walked away from my study abroad experience with a new definition for relationshipswhat it truly meant to care for someone else and love them as God would love them. I also was impacted by the way my worldview had opened up. I never thought of myself as being small minded, and I still do not think I am, but it is amazing to see firsthand how different every place in the world is.

These participants wanted to "really know what I believed and why," to spend "time trying to work through feelings," and to try and understand "why some live in horrible situations and others do not." They expressed a desire to work "at being positive" and a willingness to try to "deal with" the disparities they saw in the pain and suffering of the people, as opposed to the seeming unfair advantages that those in the United States have. Each of these entries was reflective of the majority of students who maintained positive attitudes and described motivation towards growth (see Table 2).

\subsubsection{Stress and imbalance}

There were $55(76 \%)$ of the participants who described a general sense of imbalance and stress experienced in preparation for, during and/or after their return. One participant noted that "I was forced out of my comfort zone. I faced trials and grief and death and I had to overcome it. People were diagnosed with AIDS all around me and I had to be able to accept that I could not change the entire world ...." Another wrote:

It was challenging in itself to move to another country for 3.5 months for the fact that I moved, ate different food, took classes in buildings that were unlike [name of university] classrooms, and ultimately had to be adaptable. This was easier at times, and harder at other times... We went to clinics, a hospice facility, and homes and saw the destruction that poverty and AIDS caused, yet we had to suffer through the hopelessness of not having an answer to that perpetual problem that is so rampant in the country. 
Table 2. Sampling of affirmative traits, attitudes, and motivational descriptors

\begin{tabular}{|c|c|c|}
\hline Category & $\mathbf{N}$ & Characteristics of participants \\
\hline Relationship with others & 39 & $\begin{array}{l}\text { serves, loves, mindful of, compassionate, socially confident, maintains relationships, advocates } \\
\text { for, passion for, lives for, helps, values, understanding, strong relationships with, appreciates, a } \\
\text { friend to, listens to, intentional in relationships with, maintains relationships with, forgives, feels } \\
\text { accepted by, engages, listens without judgment }\end{array}$ \\
\hline Spirituality & 22 & has faith in God \\
\hline Global awareness & 18 & $\begin{array}{l}\text { gains a global perspective, loves their country and recognizes privilege, broadens perspective, } \\
\text { engages with the community, opens eyes to see others in new ways }\end{array}$ \\
\hline Adaptability & 12 & is flexible, adjusts, moves out of comfort zone, adventurous, open-minded \\
\hline Motivation & 11 & $\begin{array}{l}\text { knows what they want, has life direction, has direction for future, believes they can change the } \\
\text { world, strives }\end{array}$ \\
\hline Positivity & 9 & feels blessed, grateful, thankful, humble, appreciative of the opportunity \\
\hline Self-confidence & 9 & $\begin{array}{l}\text { believes they can change the world, able, self-reliant, adventurous, self-reliant, knows what they } \\
\text { want, can change the world }\end{array}$ \\
\hline Stable emotions & 6 & not anxious, worry free, welcomes change, not easily frustrated \\
\hline Leadership ability & 2 & leads others \\
\hline
\end{tabular}

Among the entries were descriptions of stress and imbalance that included words and phrases such as: "overwhelmingly lonely and insecure", "homesick", "missing loved ones and friends", and feeling a "lack of power". $25 \%$ of the participants $(\mathrm{N}=18)$ wrote specifically about struggling to deal with their circumstances without the support to which they were accustomed. The food was different, the cultural was unfamiliar, and relationships were often a struggle. There were $29(40 \%)$ participants who wrote about relationship problems, either with others abroad and at home. They felt stress when trying to communicate in a foreign language and the alienation and rejection of others. Slowing down the "pace of life" was also difficult for many as the pace was so different from home. They began to ask questions such as "Why did God want me there?" and found it often just "too hard to comprehend..." what they were experiencing.

They wrote about experiencing feelings of "hopelessness, powerlessness, and confusion, regarding not only their situation, [but] also the immense pain and suffering they witnessed." They journaled about the injustice they saw all around them as they worked with the people in the clinics and community service sites who were suffering extreme poverty, and facing illness and death with little resource available to them. Twenty-three (32\%) participants wrote of the "devastating diseases plaguing the people" and leaving children orphaned and alone. The devastation felt by some as the result of "witnessing the direct impact of poverty as those we became friends with had family members die and they themselves actually passed away while we were there," was almost palpable in these entries. According to one participant, the experience "changes your perspective [and] turns your world upside down.” Another participant put it this way:

While I was there one of the most significant challenges was seeing and learning about injustice but not knowing at all what to do about it. This has become one of my biggest concerns now-what to do about injustice and how to change it in a healthy way. Another challenge was coming to terms with myself: my lack of power, character, independence, and maturity. The biggest challenge, however, was after I got back and I felt no one understood me or cared, and I just didn't know what to do with all that I learned.

They were out of their "comfort zone" in this new world, often stressed and feeling unbalanced.

\subsubsection{Letting Go: Grieving}

The stress and imbalance that was so often expressed forced the issue of how they were going to deal with their new world. Were they going to be able to let go of the world they knew at home and embrace this new one? Were they going to be able to grieve what was no longer true, so that they could "be open to rework their own values, beliefs, and relationships with others?" For many the answer was yes. Twenty-six (36\%) participants indicated their willingness to "move out of their comfort zone" and as their "eyes were opened" to broaden their perspective. Letting go was required. One participant wrote:

Challenges I faced abroad was standing face to face with HIV. The fear of contracting HIV, even 
though the chances are so minimal, through clinical practice was real for me and I feel like it inhibited me in many ways to really love the people. The challenge was that most of me was acting like a person who avoided the lepers, the invalid, the low of the low in biblical history. Jesus loved those people. My challenge was coming to terms of my real human fears that I didn't know I had until I had traveled to [country of sojourn].

Participants also wrote about having their hearts and minds prepared even before they went on their sojourn so that they would be able to engage in the study abroad opportunity, "letting the experience be the teacher," being open to learning, opening themselves up to the experience, "expanding" their comfort zone, discovering the pain, "not turning away when things were uncomfortable and painful," "moving" from one place emotionally to another, choosing to live for others rather than for themselves, "working through," "facing," "dealing with," "learning to live with," "having to push through," "facing challenges," "accepting" what was happening and their place in it, "suffering through hopelessness," and "striving to live with a radical love."

\subsubsection{Reworking, making sense, and mastery}

This letting go and engaging in the grieving process gave way to a rebalancing and adapting to their evolving world. It involved an ability to alter previous values and beliefs about life, as well as relationships with self, others and the environment, to match their new experiences/new reality. For one participant, letting go and then reworking and making sense of their study abroad experience meant being able

to see the causes of its poverty and the country's resolutions to those problems whether they were working or not. I was able to compare and contrast this new country to my own while living in this new country (not just reading about it in an article or hearing about it from stories). I was able to extract the pain and suffering and hardship that [this country] has endured but also find joy and reconciliation and forgiveness in the country as a whole...

As participants reworked their understanding of their worlds, their "view of self and others" and on "serving" others changed. They "gained a different sense of life and people". This "totally changed their idea of "needs" as they could now "invest in the lives of others more fully" and be "stretched". This process was described as a "thorough

Published by Sciedu Press deconstruction of my world view... a difficult rebuilding process" that led to a new direction and life purpose, by one participant. Another participant described it as a "reshaping [of] my view of serving, reshaping [of] my view of myself and my own abilities and how that related to serving, finding meaning in all experiences, dealing with the willingness to be open, and more..." Yet another participant wrote that their experience

completely changed my view of needs. Less interested in technology or having the latest technology. Feel more guilt/aware of spending money and how much things cost. Designer jeans have left my wardrobe for good. I am constantly searching for ways to serve those around me and hopefully a way to go back. I feel that those around me can't fully understand me until they have been to [country of sojourn].

Forty-eight (67\%) participants described the process of evaluating their own values and beliefs and how they were making sense of who they were as individuals in relationship to others and their world. Their viewpoints on morality, such as what they believed to be right and wrong and what acting justly really entails, were challenged. Their religious beliefs and faith values, as well as their perspective on culture, were impacted as they were faced with religious beliefs and values, and cultural norms and practices much different than their own. How they saw themselves in relationship with others was questioned and new perspectives embraced. They described an increase in such things as "understanding," "tolerance," loving "deeply," and their ability to "engage with people who seem different than myself," "learn from others," "care for someone and love them as God would love them," and "listen without judging or criticizing."

\subsubsection{Disillusionment, transformation and action}

The turning upside down of their world and the adaptation process whereby these students had to change in order to meet the demands of their new situation, were clearly evident in the many entries related to the participants' experiences of disillusionment and/or transformation while abroad and after return. Among the 72 participants, there were 144 references to their wellbeing either while abroad and/or after returning. They wrote about their perceptions of their physical ( 1 entry, 1\%), intellectual (32 entries, 15\%), spiritual (26 entries, 12\%), emotional (20 entries, 9\%), social (45 entries, $35 \%$ ), and/or unspecified aspects of their health. Among these responses were 124 entries (58\%) where participants described some aspect of the transformative nature of their experience. The remaining 20 entries (9\%) were descriptions of disillusionment. 
Disillusionment was described by participants who expressed feelings of confusion, anger, disappointment, powerlessness, pessimism, shock, discouragement, and/or frustration. Some wrote with a flare of anger and discontent, describing their experiences as ones that led to "profound disappointment." They remained filled with disgruntlement, in a more permanent state of disillusionment, not being able to successfully engage in a transformative process. One such participant wrote:

Other students on it ruined the trip for me... I didn't get much out of it. I realize that the experiences I had were amazing, and I am grateful for them, but those wonderful things are hard to remember in the midst of the bad things that stick out to my memory more... I did not learn anything. People always ask, "Are you remembering what you learned and applying it to your life back home?" but they fail to ask the prerequisite question, "Did you learn anything while studying abroad?" I learned nothing, therefore I had nothing to take back.

Others participants described themselves as feeling helpless, exhausted, still dealing with the "heavier things" they encountered, being "more confused than ever," not knowing where to start, and without the support they needed. However, these participants' answers suggested that they were still putting forth efforts to "reflect back" on their experience and deal with the grief they were still feeling months and even years after they returned from abroad. This struggle towards transformation is evident in the following entry:

It has changed a big chunk of who I am today. I thought I knew what I wanted to do, but after experiencing what I have, I am more confused than ever. I feel like there are so many things that should be done but I don't even know where to start. My view of the world I feel has also grown and I know things from outside of the American bubble many are in.

This participant, like others, was still dealing with the disequilibrium and stress of the study abroad and reentry experience, and again working through the process towards hopeful transformation.

Illumination, self-awareness, confidence, flexibility, opening of their intellectual, emotional and/or spiritual eyes, passion, optimism, and adventure emerged among the many descriptors of transformation shared by hopeful and transforming participants. For those who recognized elements of transformation within themselves, they wrote of being more "adaptable, flexible, understanding, capable and confident."

I learned that I was much more adaptable to new environments and to change than I had thought. I learned how much I enjoy experiencing a culture different than my own. I came away with a passion for fighting against the spread of HIV/AIDS and advocating for those infected with or affected by the disease. I came away with a new sense of prioritizing needs, and it took me awhile to accept the privileges I have in the United States for literally everything (food, shelter, hot water, health care, democracy, etc.) instead of being resentful of those privileges once I returned. I learned to be more adventurous and less fearful of change.

After their return, they saw themselves as better listeners, leaders, thinkers, problem-solvers, and speakers. They believed that they had developed more of a global perspective and an understanding as to where they fit within the world. They were ready to "pay more attention to the world and view myself as a global citizen, not just a citizen of my city." Their faith had expanded and they had come to believe in "God's bigger picture" of the world. They expressed that they "valued people and life more" and were more willing to help others through "purposeful community engagement."

It strengthened my desire to live and serve in a developing country as a nurse. It increased by understanding of community development and how nursing and community development go hand in hand, especially in developing countries. I appreciated the opportunities to work alongside and learn from [country of sojourn] nurses, especially at the hospice center. Being a part of the home-based HIV/AIDS hospice program (city of sojourn), has shaped by long-term goals/dreams.

Nursing participants, in particular, often expressed a more sobering perspective of their role in healthcare, but at the same time, a willingness to "make a difference" in their sphere of influence. They were readying themselves to take action. For example, one nurse participant wrote:

It completely changed my worldview. I used to be so self-involved, worrying about my future plans, current relationships, and academic success. Now I'm not so worried about those aspects of my life, although I still strive to do

ISSN 1925-4040 E-ISSN 1925-4059 
my best in everything. Now I am more focused on what I can do to help others. I'm going on a mission trip with [university] this summer. I'm looking into joining the Peace Corps after I graduate. It's really changed my tentative future plans....

They expressed the desire to advocate on behalf of those with catastrophic diseases such as HIV and AIDS. They wrote of returning abroad and "serving in a developing country as a nurse," for example, by joining a foreign service organization. Still others wanted to explore ways of using tangible resources they had access to more effectively, and finding other new ways to fulfill their "calling". This desire to make a difference in their world was evident even in their recommendations for program improvement.

\subsection{Recommendations for improvement}

The first area of advice offered, program and administration, made up $25 \%$ of the recommendations. Twelve $(60 \%)$ were from B.A./B.S. participants and eight (40\%) from B.S.N. participants. These recommendations centered around such things as communication between the home university and officials abroad, increased opportunities for nursing students to develop their academic and clinical skills, the desire for even more involvement with local professionals that could teaching courses, organization and communication with students regarding program issues, leadership qualifications, and academic rigor.

The next area of advice given, purpose for studying abroad, made up $9 \%$ of the concerns. Four (57\%) were from B.A./B.S. participants and three (43\%) from nursing B.S.N. participants. These comments focused primarily on recognizing students who were seemingly "not there for the right reasons." The advice was to institute live interviews as part of the admissions process in order to identify student goals for participation and decide whether or not they were a good "fit" for the experience.

Requests for additional cultural immersion opportunities were the third area of recommendation. These entries made up $20 \%$ of the recommendations; 11 (65\%) B.A./B.S. participants and six $(35 \%)$ from B.S.N. participants. The requests centered primarily around the desire for more opportunities to engage in the culture, more integration with local professionals and lay people on and off campus, and more freedom to "explore" in general. Some acknowledged the concern of the administration around safety issues that limited their freedom to explore, but recommended increasing home stay opportunities time at service sites and in other community settings.
The final area of recommendation was about student support and comprised over $44 \%$ of the responses. Nine (11\%) recommendations were focused on the pre-departure phase, nine $(11 \%)$ focused on support while abroad, and 17 (21\%) focused on the reentry phase. Recommendations related to pre-departure focused primarily on the need for more information about what to expect while abroad, both tangibly and emotionally, and the need for team building and relationship development before they went abroad. Recommendations regarding their need for support while abroad were primarily around social and emotional support. Increasing the availability of one-to-one interaction with leadership, support staff, and small support groups were among the positive support appreciated and encouraged.

The remaining 17 (20\%) entries related to student support dealt primarily with the re-entry phase. The focus was on re-entry shock and subsequent readjustment after return. Participants repeatedly expressed their need to be able to debrief their experience, to be heard, understood, and accepted where they were physically, emotionally, socially, spiritually and intellectually. They needed opportunities to share their story with others. One participant summarized their experience as follows:

My eyes were opened to the world, especially the pain and injustice and suffering ... I came back and did not have anyone to talk to about the trip, no one really wanted to listen... I still haven't been able to process it ... So right now I'm in a situation where I have a lot that, first of all, I don't feel like anyone really, really cares, about my life experience, and secondly stuff is backed up in my heart from 3 years ago that I still haven't been able to process.

Suggestions regarding opportunities for students to share their experiences and work through the "stuff" ranged from program sponsored debriefing sessions and support groups, to individual and small group mentorship opportunities, study abroad alumni activities, and to opportunities to share their experience publically through public forums, professional workshops, conferences, and creative arts displays/productions.

\subsection{Comments of appreciation}

In addition to the various recommendations, there were a number of comments regarding appreciation for the program. The experience was "phenomenal," and "I have nothing negative to say... great job... Make it more available to more students! [Offer] more opportunities for nursing students!" "It was amazing! I think about it all the time and realized I 
gained a lot from it. We just had a reunion last night and I realized again how great that semester was." "[I]t allowed me to see a totally different view of health care and appreciate the system that we have in place in the US more. It gave me opportunities to use my nursing skills and creative thinking skills in the nursing setting." The opportunities to learn, to reach out to others, to engage in "hands-on" service to others, to experience others as "beautiful" and worthy of love, and to learn to rely on their spiritual resources in difficult circumstances, all contributed to what many experienced as one of the most "amazing, unforgettable" educational experiences of their life.

\section{Discussion}

The experiences shared by each of the participants in this study were very candid and personal, and at the same time communal. Together their stories painted a lived example and thus a vital framework for understanding the transformational process of study abroad, as well as potential obstacles that can sabotaged students' transformations. Understanding the significance of the five main elements of the Transformational Study Abroad Process Model (see Figure 1) extrapolated from participant responses provides beginning insights into ways nursing educators can maximize student academic success through curriculum design and support programming.

Discerning how best to assess the traits, attitudes and motivation of students who are well-suited for study abroad, and to spot when a particular student is exhibiting opposing characteristics is an important consideration for the intake process, as well as for curriculum development and support programming. Recognizing the motivational aspect of stress and maximizing its value as it happens, while at the same time having curriculum and support programming in place so that stress and imbalance does not impede their learning is also important.

Similarly, insight into the grieving process as part of the letting go:

Grieving of studying abroad gives both faculty and students context for their suffering and loss, as well as hope for future gain through letting go of obsolete values, beliefs, and relationships to self and others, and embracing their new and expanded world. Creating curriculum and support programming opportunities to help students with the grieving, and the reworking, making sense and mastery related to the study abroad experience is also essential to the transformational process. Recognizing that this process is not isolated to a given point in time while studying abroad, but happens over time, and that times of disillusionment, disappointment, anger, confusion, fear and sadness, may be necessary for transformation; an unfolding process of positive physical, cognitive, emotional, social and/or spiritual growth and sense of well-being resulting in the development of sensitive, globally competent professionals ready to enter the workplace and make a positive difference in the world.

Limitations to the external validity of the study exist due to the small purposive sample size, the possible researcher bias given her role in program development for the bachelor in nursing population, and the limited generalizability to similar representative samples of study abroad alumni. However, the value of the study remains intact. The expansive literature review and inclusion of a multi-theorist framework as a foundation for the study, the rigorous and systematic collection process, the organized analysis conducted, the depth and consistency of responses, and the exploration of alternative themes identified, as well as the holistic and openness to potential negative consequences of the study abroad experience, all lend evidence to the credence, and thus the internal and external credibility and trustworthiness of this study.

\section{CONCLUSION AND CHALlenge TO NURS- ING EDUCATORS}

Educators involved in the provision of study abroad opportunities for students must take seriously all aspects of the transformation process of study abroad as evidenced in this current study. This involves not only understanding the process in its totality, but asking questions and implementing programming based on the answers. See Table 3 for sample questions. For nurse educators, in particular, stimulating the metamorphosis from nursing students to capable professional novice nurses ready to enter the workforce and contribute to the provision of healthcare in the global society of the $21 \mathrm{st}$ century must be a goal of the academic nursing community. If nursing students are indeed going to reap the full benefit of the study abroad experience, it behooves nurse educators, as well as others involved in college and university study abroad programming, to re-evaluation their curriculum and support programming and ask new questions in order to ensure that all aspects of transformational process of studying abroad; before, during and after, have to be carefully considered.

The theoretical framework for the transformational process of study abroad that emerged from the literature not only provided a launching pad for this study, but a point of reference 
for understanding the experience of the participants in this study. The richness of the student responses to the survey questions provided vivid insight into not only their process, but also offered valuable information essential to discerning student needs, both curricular and supportive, before, during and after studying abroad. This research, however, is only a starting point. Not only is it important that research be conducted with different populations of students, but closer examination of each element of the process is warranted.

Table 3. Transformation model of study abroad. Curricular and support programming considerations

\begin{tabular}{|c|c|}
\hline $\begin{array}{l}\text { Components of the } \\
\text { Transformational Process }\end{array}$ & Questions for nursing educators to consider \\
\hline $\begin{array}{l}\text { 4.1.1 Traits, attitudes, and } \\
\text { motivation }\end{array}$ & $\begin{array}{l}\text { - What traits, attitudes and behaviors indicative of success will we look for in potential study } \\
\text { abroad students? } \\
\text { - How will we determine the presence or absence traits, attitudes and behaviors indicative of } \\
\text { success in potential study abroad students? } \\
\text { - What curriculum and support programming needs to be included in the program to maximize } \\
\text { these assets and develop them in students when lacking? }\end{array}$ \\
\hline 4.1.2 Stress and imbalance & $\begin{array}{l}\text { - How will we prepare students for the stress and imbalance they will face throughout the study } \\
\text { - Whroad experience? } \\
\text { before, during, after? } \\
\text { - What content needs to be included in the curriculum and where to address the experiences } \\
\text { culture shock and reverse shock students will encounter? }\end{array}$ \\
\hline 4.1.3 Letting go: Grieving & $\begin{array}{l}\text { - What experiences will be built in to the curriculum and support programming to help prepare } \\
\text { students to "move” out of their comfort zone" and at the same time provide them with the } \\
\text { needed safety physically, emotionally, socially, spiritually and mentally to thrive. } \\
\text { - Are there mental health services that we need to build into the program before, during and after } \\
\text { to help students with the grieving process? } \\
\text { - What other support services do we need to be prepared to offer students during and after they } \\
\text { study abroad, and for how long? } \\
\text { - How will we identify students who are at risk of getting "stuck" in the grieving process? I.e. } \\
\text { how will we know if a student is struggling with adjustment issues, anxiety, depression, etc.? }\end{array}$ \\
\hline $\begin{array}{l}\text { 4.1.4 Reworking, making sense, } \\
\text { and mastery }\end{array}$ & $\begin{array}{l}\text { - What community engagement/clinical/service experiences will we provide the students that } \\
\text { will challenge their understanding of themselves in relationship to others and expand their } \\
\text { - Worldview? } \\
\text { - What curricular content do students need to develop their cultural sensitivity? } \\
\text { make sense of their experiences? }\end{array}$ \\
\hline $\begin{array}{l}\text { 4.1.5 Disillusionment and/or } \\
\text { transformation }\end{array}$ & $\begin{array}{l}\text { - How will we evaluate the success of the program in terms of student transformation? } \\
\text { - What support services are available to students during and after their study abroad to help them } \\
\text { work through experiences of disillusionment during and subsequent to their study abroad } \\
\text { experience? } \\
\text { - What opportunities will be put into place for students to tell their stories regarding their study } \\
\text { abroad experience? } \\
\text { - What curricular and/or support programming will we make available to alumni who studied } \\
\text { abroad while in their baccalaureate programs? }\end{array}$ \\
\hline
\end{tabular}

Future research also needs to include but not be limited to: exploring more completely the characteristics of those who transform and how to either maximize these characteristics and/or develop them in students to increase positive coping, identifying how best to engage students in the grieving pro- cess in order that they can move more effectively towards transformation, investigating the presence of psychological problems and possible interventions related to the stress and imbalance and/or disillusionment of study abroad, and comparing the benefits received by nursing students who study 
abroad versus those that participate in other cross-culture experiences offered within the university setting. If indeed studying abroad is to be an "opportunity of a lifetime" for transformation, then La Brack's warning from over 30 years ago, to "bring the whole person back", must be heeded. ${ }^{[74]}$
Further research that results in truly holistic study abroad curricular and support programming for nursing students is thus warranted.

\section{CONFlicts OF INTEREST Disclosure}

The author declares that there is no conflict of interest.

\section{REFERENCES}

[1] AACN. curriculum guidelines [Internet]. Washington (D.C.): American Association of Colleges of Nursing: c 2017 [cited 2017 Sept 1]. Available from: http://www. aacn.nche.edu/education-r esources/curriculum-standards

[2] Duffy ME, Farmer S, Ravert P, et al. International community health networking project: two-year follow-up of graduates. International Nursing Review. 2005; 52/1: 24-31. PMid:15725273 https://doi.org/10.1111/j.1466-7657.2004.00252.x

[3] Kollar, SJ, Ailinger RL. International clinical experiences: Long-term impact on students. Nurse Educator. 2002; 27(1): 28-31. Available from: http://journals.lww.com/nurseeducator online/Abstract/2002/01000/International_Clinical_ Experiences__Long_term.16.aspx

[4] Koskinen L, Tossavainen K. Relationships with undergraduate nursing exchange students - a tutor perspective. Journal of Advanced Nursing. 2002; 41: 499-508. https://doi.org/10.1046/j.13 65-2648.2003.02562.x

[5] Ruddock HC, Turner de S. Developing cultural sensitivity: Nursing students' experiences of a study abroad program. Journal of Advanced Nursing. 2007; 59(4): 361-369. PMid:17608686 https : //doi.org/10.1111/j.1365-2648.2007.04312.x

[6] Comp DJ compiler. Research on U.S. students abroad "additional resources": A bibliography with abstracts, 1988-2000. Chicago, Il: University of Chicago Office of International Affairs; 2017. Available from: http://www.globaled.us/ro/book_research _chao_add.asp

[7] Comp DJ compiler. Research on U.S. students study abroad: An update, volume III, 2001-2003, with updates to the 1989 and volume II editions 2000-2003. Chicago, Il: University of Chicago Office of International Affairs; 2017. Available from: http:/globaledres earch.com/book_research_comp.asp

[8] Comp DJ, Biscarra A. compilers. Research on U.S. students study abroad: An update, 2003-Earlier. A bibliography with abstracts Dominguez Hills, CA: California State University Center for Global Education; 2017. Available from: http://globaledresearch.c om/book_research_comp_update. asp?year $=2003$

[9] Comp DJ, Biscarra A. compilers. Research on U.S. students study abroad: An update, 2004-2011. A bibliography with abstracts Dominguez Hills, CA: California State University Center for Global Education; 2017. Available from: http://globaledresearch.c om/book_research_comp_update. asp?year $=2004$

[10] Parcells C, O'Brien MK, Woodrugg G, compilers. Internationalizing the Curriculum and Campus. Bibliography: Internationalizing Higher Education. Minneapolis (MN): University of Minnesota Global Programs and Strategy Alliance; 2013. Available from: https://global.umn.edu/icc/documents/bibliogra phy_intlz_higher_ed.pdf

[11] Weber WM. A literature review of the reentry and adjustment experience of college students returning from short-term international Chris- tian mission experiences and implications for student affairs professionals [Master's thesis]. [Manhattan (KS)]: Kansas State University; 2009. Available from: http://citeseerx.ist.psu.edu/view doc/download?doi=10 1 1 1 .540.9826\&rep=rep1\&type=pdf

[12] Levine MA, Perpetua E. International immersion programs in baccalaureate nursing education: Professor and student perspectives. Journal of Cultural Diversity. 2006; 13(1): 20-26. PMid:16696541

[13] Black JS, Mendenhall M. Towards a comprehensive model of international adjustment: An integration of multiple theoretical perspectives. Academy of Management Review. 1991; 16(2): 291-317. Available from: https://scholar.google.com/cit ations?view_op=view_citation\&hl=en\&user=UAGF $2 x c A A A$ AJ\&citation_for_view=UAGF $2 x$ cAAAAJ : u5HHmVD_u08C

[14] Dodd CH. Intercultural readiness assessment for pre-departure candidates. Intercultural Communication Studies. 2007; 16(2): 1-17.

[15] Irwin R. Culture shock: Negotiating feelings in the field. Anthropology Matters Journal. 2007; 9(1).

[16] Mumford DB. The measurement of culture shock. Social Psychiatry Psychiatric Epidemiology. 1998; 33:149-154. PMid:9567664 https://doi.org/10.1007/s001270050037

[17] Brown HE. Sojourner adjustment among undergraduate students: Relationships with locus of control and coping strategies (Doctoral dissertation). Dissertation Abstracts international. 1998 Oct; 59(4): 1912B

[18] Thompson CL, Christofi V. You cannot go home again: A phenomenological investigation of returning to the sojourn country after study abroad. Journal of Counseling and Development. 2007; 85: 5363. https://doi.org/10.1002/j.1556-6678.2007.tb00444 . $\mathrm{x}$

[19] Chamove AS, Soeterik S M. Grief in returning sojourners. Journal of Social Sciences. 2007; 13: 215-220. Available from: http://krepublishers. com/02-Journals/JSS/JSS-13-0 -000-000-2006-Web/JSS-13-3-000-000-2006-Abst-Text/ JSS-13-3-215-220-2006-403-Chamove-A/JSS-13-3-215 -220-2006-403-Chamove-A-Text.pdf

[20] Davis DC, Chapman D, Bohlin B, et al. Reverse culture shock: A comparison of United States and Japanese students' experiences returning from a study abroad sojourn. The NCA 94th Annual Convention, 2008; San Diego, CA. Available from:http://www . alla cademic.com/meta/p259784_index.html

[21] Evanson TA, Zust BL. The meaning of participation in an international service experience among baccalaureate nursing students. International Journal of Nursing Education Scholarship. 2004; 1(1): 1-14. https://doi.org/10.2202/1548-923x.1070

[22] Gaw KF. Reverse culture shock in students returning from overseas. International Journal of Intercultural Relations. 2000; 24: 83-104. https://doi.org/10.1016/S0147-1767 (99)00024-3

[23] Rashio RA. College students' perceptions of reverse culture shock and reentry adjustments. Journal of College Student Personnel. 1987; 156-162. Available from: http://www . worldcat.org/search? 
q=ti $\% 3 \mathrm{ACollege+students} \% 27+$ perceptions+of + reverse+ culture+shock\&qt=advanced\&dblist $=638$

[24] Tonkin H, Quiroga D. A qualitative approach to the assessment of international service-learning. Frontiers: The Interdisciplinary Journal of Study Abroad. 2008; 10: 121-149.

[25] Weber WM. A literature review of the reentry and adjustment experience of college students returning from short-term international Christian mission experiences and implications for student affairs professionals [Master's thesis]. [Manhattan (KS)]: Kansas State University; 2009. Available from: http://citeseerx.ist.psu.edu/view doc/download?doi=10.1.1.540.9826\&rep=rep1\&type=pdf

[26] Dukes R, Johnson R, Newton H. Long-term effects of travel and study: The Semester at Sea Program. Psychological Reports. 1991; 68: 563-570. Available from: http://journals. sagepub.com/d oi/pdf/10.2466/pr0.1991.68.2.563

[27] Evanson TA, Zust BL. The meaning of participation in an international service experience among baccalaureate nursing students. International journal of Nursing Education Scholarship. 2004; 1(1): 1-14. Available from: https://doi.org/10.2202/1548-923x.1070

[28] Kollar SJ, Ailinger RL. International clinical experiences: Long-term impact on students. Nurse Educator. 2002; 27(1): 28-31. Available from: http://journals.lww.com/nurseeducatoronline/A bstract/2002/01000/International_Clinical_Experien ces__Long_term.16.aspx

[29] Koskinen L, Tossavainen K. Study abroad as a process of learning intercultural competence in nursing. International Journal of Nursing Practice. 2004; 10: 111-120. PMid:15149458 https: //doi.org/10.1111/j.1440-172X.2004.00470.x

[30] Lester JC. Strangers in their own land: Culture loss, disenfranchised grief, and reentry adjustment. Dissertation Abstracts International: Section B: Sciences and Engineering. 2001 Mar; 61(9-B): 4992.

[31] Levine MA, Perpetua E. International immersion programs in baccalaureate nursing education: Professor and student perspectives. Journal of Cultural Diversity. 2006; 13(1): 20-26. PMid:16696541

[32] Davis DC, Chapman D, Bohlin B, Jaworski BE. Walley CM, Barton DA, Ebner N. Reverse culture shock: A comparison of United States and Japanese students' experiences returning from a study abroad sojourn. The NCA 94th Annual Convention, 2008; San Diego, CA. Available from: http: //www. allacademic.com/meta/p259784 _index.html

[33] Irwin R. Culture shock: Negotiating feelings in the field. Anthropology Matters Journal. 2007; 9(1).

[34] Lester JC. Strangers in their own land: Culture loss, disenfranchised grief, and reentry adjustment. Dissertation Abstracts International: Section B: Sciences and Engineering. 2001 Mar; 61(9-B): 4992.

[35] Levine MA, Perpetua E. International immersion programs in baccalaureate nursing education: Professor and student perspectives. Journal of Cultural Diversity. 2006; 13(1): 20-26. PMid:16696541

[36] Weber WM. A literature review of the reentry and adjustment experience of college students returning from short-term international Christian mission experiences and implications for student affairs professionals [Master's thesis]. [Manhattan (KS)]: Kansas State University; 2009. Available from: http://citeseerx.ist.psu.edu/view doc/download?doi=10.1.1.540.9826\&rep=rep1\&type=pdf

[37] Chamove AS, Soeterik SM. Grief in returning sojourners. Journal of Social Sciences. 2007; 13: 215-220. Available from: http://krepublishers.com/02-Journals/JSS/JSS-13-0 -000-000-2006-Web/JSS-13-3-000-000-2006-Abst-Text/ JSS-13-3-215-220-2006-403-Chamove-A/JSS-13-3-215 -220-2006-403-Chamove-A-Text.pdf

[38] Thompson CL, Christofi V. You cannot go home again: A phenomenological investigation of returning to the sojourn country after study abroad. Journal of Counseling and Development, 2007; 85: 5363. https://doi.org/10.1002/j.1556-6678.2007.tb00444 $\mathrm{x}$

[39] Foronda C. Associate degree nursing students' thoughts, feelings, and experiences of short study abroad in a low-income country (Doctoral dissertation). 2010.

[40] Kollar SJ, Ailinger RL. International clinical experiences: Long-term impact on students. Nurse Educator. 2002; 27(1): 28-31. Available from: http://journals.lww.com/nurseeducatoronline/A bstract/2002/01000/International_Clinical_Experien ces__Long_term.16.aspx

[41] La Brack B. State of the art research on re-entry. An essay on directions for the future. Paper presented at: The 26th Annual Convention of the International Studies Association; 1985; Washington, DC Available from: https://archive.org/details/ERIC_ED257 701

[42] La Brack B. The missing linkage: The process of integrating orientation and reentry. In: Paige, $M$, ed by. Education for the Intercultural Experience. Boston, MA: Nicholas Brealey Publishing.

[43] Leininger M. Nursing education exchanges: Concerns and benefits Journal of Transcultural Nursing, 1998; 9(2): 67-71. PMid:9856014 https ://doi.org/10.1177/104365969800900212

[44] Lester JC. Strangers in their own land: Culture loss, disenfranchised grief, and reentry adjustment. Dissertation Abstracts International: Section B: Sciences and Engineering. 2001 Mar; 61(9-B): 4992.

[45] Mitchelson E, Latham L. The Development of a Maori Nursing Conceptual Model: Exploratory Research Phase. Wellington: Health Research Council of New Zealand; 2000.

[46] Rashio RA. College students' perceptions of reverse culture shock and reentry adjustments. Journal of College Student Personnel. 1987; 156-162. Available from: http://www.worldcat.org/search? $\mathrm{q}=$ ti $\% 3 \mathrm{ACollege+students} \% 27+$ perceptions+of+reverse+ culture+shock\&qt $=$ advanced\&dblist $=638$

[47] Black JS, Mendenhall M. Towards a comprehensive model of international adjustment: An integration of multiple theoretical perspectives. Academy of Management Review. 1991; 16(2): 291-317. Available from: https://scholar.google.com/cit ations?view_op=view_citation\&hl=en\&user=UAGF2xcAAA AJ\&citation_for_view=UAGF $2 x c A A A A J:$ JHHmVD_u08C

[48] Brown HE. Sojourner adjustment among undergraduate students: Relationships with locus of control and coping strategies (Doctoral dissertation). Dissertation Abstracts international. 1998 Oct; 59(4): 1912B

[49] Chamove AS, Soeterik SM. Grief in returning sojourners Journal of Social Sciences. 2007; 13:215-220. Available from: http://krepublishers. com/02-Journals/JSS/JSS-13-0 -000-000-2006-Web/JSS-13-3-000-000-2006-Abst-Text/ JSS-13-3-215-220-2006-403-Chamove-A/JSS-13-3-215 -220-2006-403-Chamove-A-Text.pdf

[50] Dodd CH. Intercultural readiness assessment for pre-departure candidates. Intercultural Communication Studies. 2007; 16(2): 1-17.

[51] Klatt-Mogro AM. A comparison of symptomatology and cultural readjustment distress measurements in acculturation and reentry (Doctoral dissertation). Dissertation Abstracts International. 1998 June; 48(12): 3682A.

[52] Koskinen L, Tossavainen K. Relationships with undergraduate nursing exchange students - a tutor perspective. Journal of Advanced Nursing. 2002; 41: 499-508. https://doi.org/10.1046/j.13 $65-2648.2003 .02562 . x$

[53] Levine MA, Perpetua E. International immersion programs in baccalaureate nursing education: Professor and student perspectives. Journal of Cultural Diversity. 2006; 13(1): 20-26. PMid:16696541 
[54] Nafziger KL. Reentry adjustment of short-term student sojourners: A test of the U-curve hypothesis [dissertation]. [Urbana: IL]: University of Illinois at Urbana-Champaign; 1996.

[55] Parcells C, O’Brien M K, Woodrugg G, compilers. Internationalizing the Curriculum and Campus. Bibliography: Internationalizing Higher Education. Minneapolis (MN): University of Minnesota Global Programs and Strategy Alliance; 2013. Available from: https://global.umn.edu/icc/documents/bibliogra phy_intlz_higher_ed.pdf

[56] Shupe EI. Clashing cultures: A model of international student conflict. Journal of Cross-Cultural Psychology. 2007; 38: 750-771. https://doi.org/10.1177/0022022107308996

[57] Tonkin H, Quiroga D. A qualitative approach to the assessment of international service-learning. Frontiers: The Interdisciplinary Journal of Study Abroad. 2008; 10: 121-149.

[58] Zorn CR. The long-term impact on nursing students participating in international education. Journal of Professional Nursing. 1996 Mar; 12(2): 106-110. https://doi.org/10.1016/S8755-722 3 (96) 80056-1

[59] Foronda, C. Associate degree nursing students' thoughts, feelings, and experiences of short study abroad in a low-income country (Doctoral dissertation). 2010; 116p.

[60] Thompson CL, Christofi V. You cannot go home again: A phenomenological investigation of returning to the sojourn country after study abroad. Journal of Counseling and Development, 2007; 85: 53 63. https://doi.org/10.1002/j.1556-6678.2007.tb00444 . $\mathrm{x}$

[61] Milstein T. Transformation abroad: Sojourning and the perceived enhancement of self-efficacy. International Journal of Intercultural Relations. 2004; 29: 271-238. Available from: https : //doi.org/ 10.1016/j.ijintrel.2005.05.005

[62] Shougee M. The experiences, meanings and outcomes of studying abroad: A Qualitative multiple-case study (Doctoral dissertation). Dissertation Abstracts International. 2000 Mar; 60(09): 3290A, 147 p.

[63] Foronda C. Associate degree nursing students' thoughts, feelings, and experiences of short study abroad in a low-income country (Doctoral dissertation). 2010.

[64] Piaget J. The equilibration of cognitive structures: The central problem of intellectual development. Chicago: University of Chicago Press; 1978.
[65] Adler NJ. Re-Entry: Managing Cross-Cultural Transitions. Group \& Organization Studies. 1981; 6(3): 341-356. https ://doi .org/10 $.1177 / 105960118100600310$

[66] Thompson CL, Christofi V. You cannot go home again: A phenomenological investigation of returning to the sojourn country after study abroad. Journal of Counseling and Development, 2007; 85: 5363. https://doi.org/10.1002/j.1556-6678.2007.tb00444 . $\mathrm{x}$

[67] Piaget J. The equilibration of cognitive structures. Chicago: University of Chicago Press. (1978/1985). As cited in Thompson CL, Christofi V. You cannot go home again: A phenomenological investigation of returning to the sojourn country after study abroad. Journal of Counseling and Development. 2007.

[68] Adler NJ. Re-Entry: Managing Cross-Cultural Transitions. Group \& Organization Studies. 1981; 6(3):85p. Cited in: Thompson CL, Christofi V. You cannot go home again: A phenomenological investigation of returning to the sojourn country after study abroad. Journal of Counseling and Development. 2007.

[69] Kim YY, Ruben BD. Intercultural transformation: A systems theory. Cited in: Kim YY, Gudykunst WB, ed by. Theories in Intercultural Communication. Newbury Park, CA: Sage Publications; 1988; 299$321 \mathrm{p}$.

[70] Bandura A. Self-efficacy: Toward a unifying theory of behavioral change. Psychology Review. 1977; 84: 191-215. As cited in: Milstein T. Transformation abroad: Sojourning and the perceived enhancement of self-efficacy. International Journal of Intercultural Relations. 2004; 29: 222-223. https://doi.org/10.1016/j.ijintrel.2 005.05 .005

[71] Milstein, T. Transformation abroad: Sojourning and the perceived enhancement of self-efficacy. International Journal of Intercultural Relations. 2004. https ://doi.org/10.1016/j.ijintrel. 200 5.05 .005

[72] Mezirow J. A critical theory of adult learning and education. Adult Education [Internet]. 1981 Fall [cited 2017, Sep 1]; 32(1): 3-24.

[73] Shougee M. The experiences, meanings and outcomes of studying abroad: A Qualitative multiple-case study (Doctoral dissertation). Dissertation Abstracts International. 2000 Mar; 60(09): 3290A, 147.

[74] La Brack B. State of the art research on re-entry. An essay on directions for the future. Paper presented at: The 26th Annual Convention of the International Studies Association; 1985; Washington, DC. Available from: https://archive.org/details/ERIC_ED257 701 